\title{
Polarographic Analysis of Titanium (IV) -EDTA Complex: Application to Paint Pigments
}

\author{
Harvey W. Berger and Barry C. Cadoff
}

(August 3, 1964)

\begin{abstract}
The Ti+4-EDTA complex, buffered at $p \mathrm{H} 4.7$, has been found to give polarographic waves suitable for the analysis of $\mathrm{TiO}_{2}$ in paint pigments. A linear relationship between diffusion current and concentration of $\mathrm{Ti}^{+4}$ for the range $2.8 \times 10^{-5}$ to $8.4 \times 10^{-3} M$ has been observed. The pigments analyzed have been either in the dry form or extracted from whole paint. The method gives results in good agreement with the more complicated and time-consuming standard wet chemical method.
\end{abstract}

Standard methods for the analysis of $\mathrm{TiO}_{2}$ in paint pigments involve rather tedious and time-consuming procedures and are also subject to several interfering ions, such as iron, chromium, and arsenic $[3,6] .{ }^{1}$ In searching for a faster, simpler method, and one which would be comparatively free of interferences, polarography was investigated. A study of the literature revealed that a variety of supporting electrolytes have been used, such as tartrate, citrate, oxalate, ethylenediaminetetraacetic acid (EDTA). These methods have been reviewed by Codell [2]. More recently, Banerjee, Budke, and Miller reported the use of a sulfuric acid-potassium persulfate medium for the determination of titanium in ores [1].

Sinyakova [5] and Pecsok and Maverick [4] studied the chemistry of the Ti-EDTA complex and found that reversible waves could be obtained over a fairly wide $p \mathrm{H}$ range. The latter authors suggested that this could be adapted to analytical uses.

This paper reports the development of a polarographic method, employing ED'TA as the complexing agent, that results in a rapid, accurate analysis of $\mathrm{TiO}_{2}$ in dry pigments or pigments extracted from paint.

\section{Experimental Detail}

\subsection{Apparatus and Reagents}

A Sargent Model XV Polarograph with a dropping mercury electrode and an H-cell were used. The cell was placed in a constant temperature bath maintained at $25.0 \pm 0.1{ }^{\circ} \mathrm{C}$. Measurements of $p H$ were made with a glass electrode $p \mathrm{H}$ meter.

Reagent grade titanium dioxide was used to determine the diffusion current constant $\left(I_{d}\right)$. This standardization and calibration was checked with National Bureau of Standards Titanium Dioxide (Standard Sample No. 154).

${ }_{1}^{1}$ Figures in brackets indicate the literature references at the end of this paper.

\subsection{Procedure}

For pure samples of titanium dioxide a maximum of $0.2 \mathrm{~g}$ was weighed to $0.1 \mathrm{mg}$ into a $100 \mathrm{ml}$ beaker and $5.0 \mathrm{ml}$ of concentrated $\mathrm{H}_{2} \mathrm{SO}_{4}$ and $1.0 \mathrm{~g}$ of $\left(\mathrm{NH}_{4}\right)_{2} \mathrm{SO}_{4}$ were added. The beaker was left uncovered, heated slowly at first and then rapidly, to fuming. After fuming for $5 \mathrm{~min}$, the solution was cooled to room temperature and $15 \mathrm{ml}$ of water was added very slowly with vigorous stirring. Two grams of the disodium salt of EDTA, dissolved in $15 \mathrm{ml}$ of $7 \mathrm{M} \mathrm{NH} \mathrm{NH}_{4} \mathrm{OH}$, was then added to the sulfuric acid solution. The $p \mathrm{H}$ at this point was approximately 1.5 and $40 \mathrm{ml}$ of $4 M$ sodium acetate-acetic acid buffer was added to bring the $p \mathrm{H}$ to 4.7 . The solution was diluted with water to a final volume of $250 \mathrm{ml}$. An aliquot was placed in the H-cell and purged with nitrogen for $10 \mathrm{~min}$. A polarogram was then run. The graphical method described by Willard, Merritt, and Dean [7] was used to determine the wave heights.

The sulfuric-acid-insoluble components, such as white lead and silica, in titanium-containing pigments caused the formation of large aggregates which could not be adequately dispersed without prolonged heating. Therefore, it was necessary to modify the method for the preparation of solutions. After fuming for $5 \mathrm{~min}$, the mixture was stirred thoroughly with a glass rod to break up any lumps of pigment. The mixture was then reheated to fuming for $1 \mathrm{~min}$. The procedure for pure $\mathrm{TiO}_{2}$ was then followed. It was found to be unnecessary to filter the mixture before running a polarogram.

\section{Results and Discussion}

\subsection{Standardization}

The data obtained for the analyses of reagent grade $\mathrm{TiO}_{2}$ are shown in table 1 . The $I_{d}$ is independent of the concentration of titanium over the range $3 \times 10^{-5}$ to $8 \times 10^{-3} \mathrm{M}$. Although for the 
purposes of pigment analysis it would be unnecessary to deal with concentrations at the lower end of the range, the method was investigated to these further limits to assess its potential for use as a general method of analysis which would be valid over a rather large concentration range.

The electrode reaction at $p \mathrm{H} 4.7$ is [4]:

$$
\mathrm{TiOY}^{-2}+2 \mathrm{H}^{+}+e^{-}=\mathrm{TiY}^{-}+\mathrm{H}_{2} \mathrm{O}
$$

where Y represents the EDTA ligand. This equation is, in fact, valid for values of $p \mathrm{H}$ from about 2.5 to 8 . Below $p \mathrm{H} 2.5$ the electrode reaction is $\mathrm{TiY}+e^{-}=\mathrm{TiY}^{-}$. From calculations using the reported values for the equilibrium constants the concentrations of $\mathrm{TiOY}^{-2}$ and $\mathrm{TiY}^{-}$are equal at a $p \mathrm{H}$ of 2.4 .

TABLE 1. Polarographic analysis of titanium-EDTA complex using reagent grade $\mathrm{TiO}_{2}$

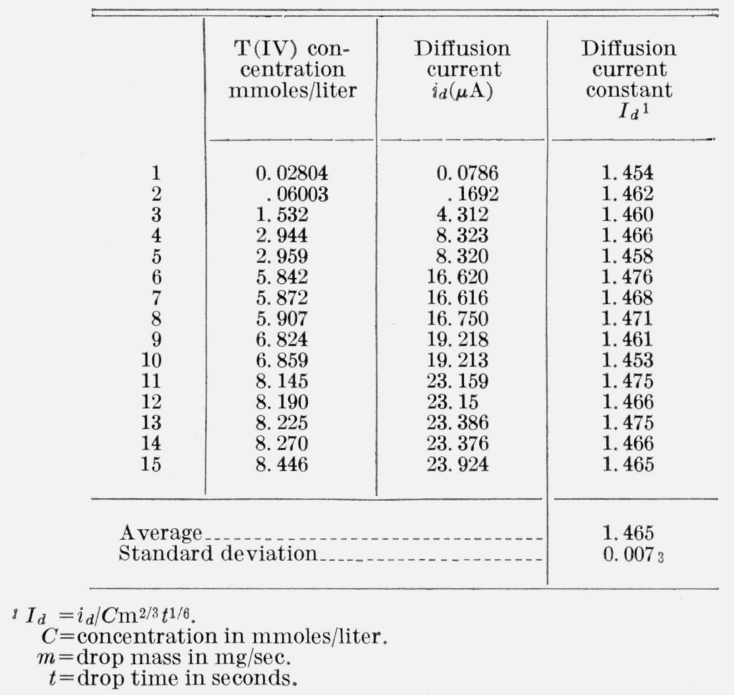

The electrode reaction taking place below $p \mathrm{H} 2.5$ was not used as the basis of an analytical procedure because the solubility of EDTA in such acidic solutions is below that which will permit the preparation of clear solutions containing $2 \mathrm{~g}$ of the disodium salt. In addition, at $p \mathrm{H} 2.5$, three forms of EDTA are present: $\mathrm{H}_{4} \mathrm{Y}, \mathrm{H}_{2} \mathrm{Y}^{-2}$ and primarily $\mathrm{H}_{3} \mathrm{Y}^{-}$. Between $p \mathrm{H} 3.5$ and 5.5, essentially the only form present is $\mathrm{H}_{2} \mathrm{Y}^{-2}$. It is preferable that only one form of the ligand be involved in the complexation reaction. At $p \mathrm{H}$ 4.7, well defined, reversible polarographic waves are obtained which have low residual currents and flat plateau regions.

\subsection{Effects of Supporting Electrolyte}

The effect of sulfate ion concentration on the diffusion current $\left(i_{d}\right)$ is shown in figure 1 . With an excess of sulfate, added during the solution step, a wave appears at $-0.7 \mathrm{~V}$. versus the Saturated Calomel Electrode (S.C.E.), (curve C). This wave, attributed to a Ti-sulfate complex (curve A) [4], is formed at the expense of the Ti-EDTA complex and begins to appear at approximately $0.7 \quad M \mathrm{SO}_{4}{ }^{-2}$.

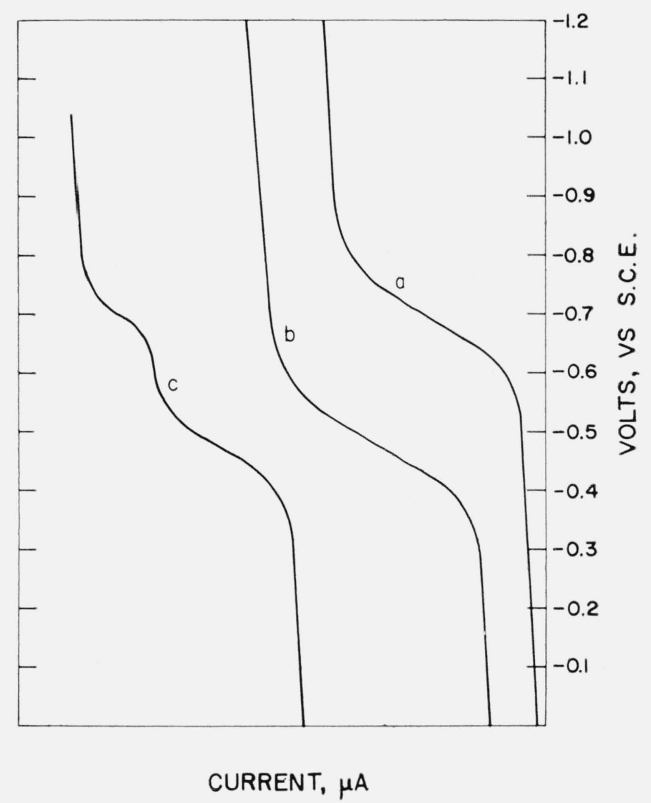

FIGURE 1. Representative polarographic curves.

a. $\mathrm{H}_{2} \mathrm{SO}_{4}$ solution of Ti(IV)-no EDTA $0.4 \mathrm{M} \mathrm{SO}_{4}^{-2} \mathrm{pH}=4.5$. b. Same as above but with EDTA $p \mathrm{H}=4.7$.

c. Same as b., but with $1 M \mathrm{SO}_{4}^{-2}$.

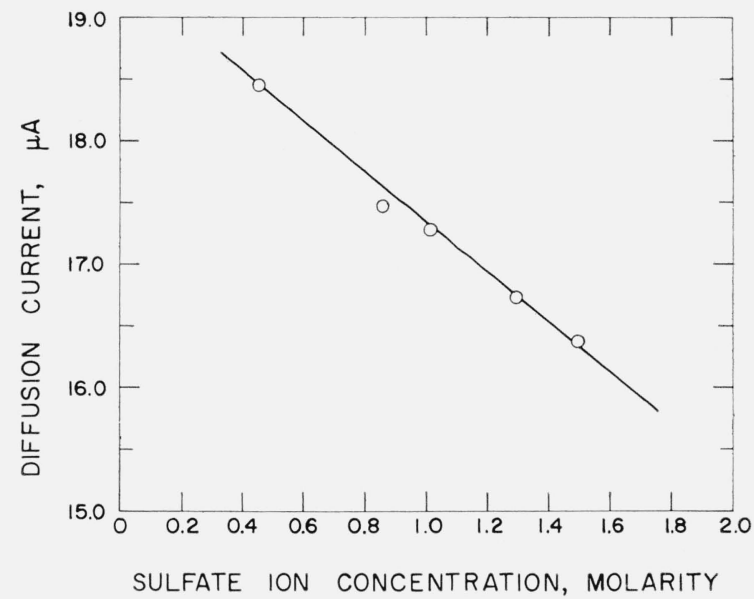

Figure 2. Effect of sulfate ion concentration on the Ti(IV)EDTA diffusion current.

The addition of a large excess of EDTA does not achieve the complete removal of this wave. The Ti-EDTA reduction wave is shown in curve B. The effect of increasing sulfate concentration on the diffusion current of the Ti-EDTA complex is shown in figure 2. There is a linear decrease of $i_{d}$, and thus a decrease in the assay of titanium, with increase in the sulfate ion concentration and it is, therefore, necessary that the sulfate concentration be kept low and constant. In the routine preparation of solutions the concentration of sulfate can be sufficiently controlled to account for less than 0.1 percent change in the diffusion current. On the other hand, the Ti-EDTA diffusion current is 
independent of the total concentration of EDTA over a range of 8 to $40 \mathrm{mM}$.

The order of addition of reagents has a pronounced effect upon the diffusion current. Addition of the buffer to the sulfuric acid solution prior to the addition of EDTA results in the formation of a different titanium complex which cannot be completely eliminated by the subsequent addition of ED'TA.

\subsection{Effect of Aging}

Figure 3 illustrates the decrease of the diffusion current with time. About one week after the preparation of solutions a yellow color became noticeable and increased in intensity with time. Erratic results were obtained if solutions were left standing more than three days.

\subsection{Effect of Temperature}

The temperature dependency of the diffusion current was studied over the range of 20 to $30{ }^{\circ} \mathrm{C}$. It was found that an increase of 1.4 percent in the diffusion current occurred for each degree rise in temperature.

\subsection{Effect of Maximum Suppressor}

No polarographic maxima were encountered in the analyses of the titanium-ED'TA solutions and no maximum suppressors were used. When some other reducible cations are in solution, however, small maxima do occasionally occur. The effect of gelatin on the titanium-ED'TA diffusion current was studied in the event that the simultaneous analysis of titanium and other cations might necessitate the presence of a maximum suppressor. The effect of gelatin on the diffusion current is shown in figure 4 . Between 0.008 percent and 0.05 percent $i_{d}$ decreases rapidly with increasing percentages of gelatin. Therefore, analyses should not be performed in this range. Lower percentages of gelatin are preferable if they succeed in eliminating maxima since maximum suppressors tend to change the values of the parameters in the Ilkovic equation, which is used to calculate $I_{a}$.

\subsection{Interferences}

A study was made of possible chemical interferences in the analysis. Weighed amounts of compounds were added in 1:1 molar ratios to the $\mathrm{TiO}_{2}$ before dissolving in sulfuric acid. $\mathrm{Al}(\mathrm{III}), \mathrm{Mg}(\mathrm{II})$, $\mathrm{Ca}(\mathrm{II}), \mathrm{Cr}(\mathrm{III}), \mathrm{Pb}(\mathrm{II}), \mathrm{Zn}(\mathrm{II})$, and $\mathrm{Fe}(\mathrm{III})$ did not interfere in the analysis. $\mathrm{Sb}(\mathrm{III})$, however, did cause interference. In all of these determinations, it was necessary to have sufficient EDTA present to fully complex the foreign cations. For example, lead and zinc will compete for EDTA and, if those cations are added to a solution in which there is not sufficient ED'TA available, the Ti-ED'TA complex will dissociate so that the preferential lead and zinc complexes will form. In such cases, a titanium wave

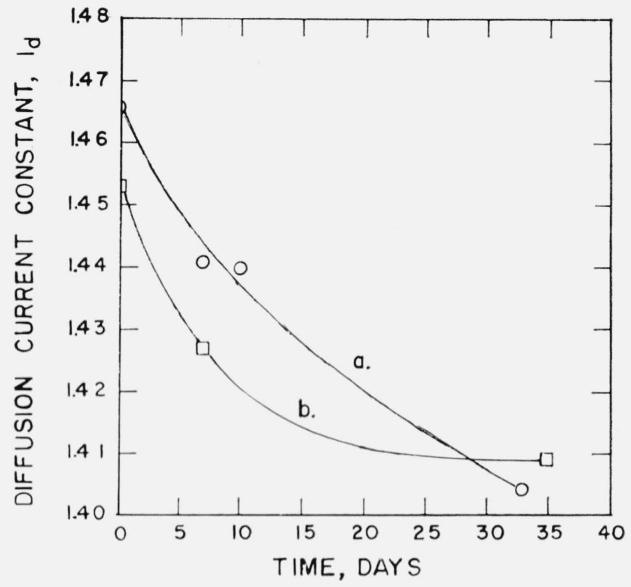

Figure 3. Effect of time on the Ti(IV)-EDTA diffusion current constant.

a. $0.1652 \mathrm{~g} . \mathrm{TiO}_{2} / 250 \mathrm{ml}$ b. $0.1370 \mathrm{~g} \mathrm{TiO}_{2} / 250 \mathrm{ml}$

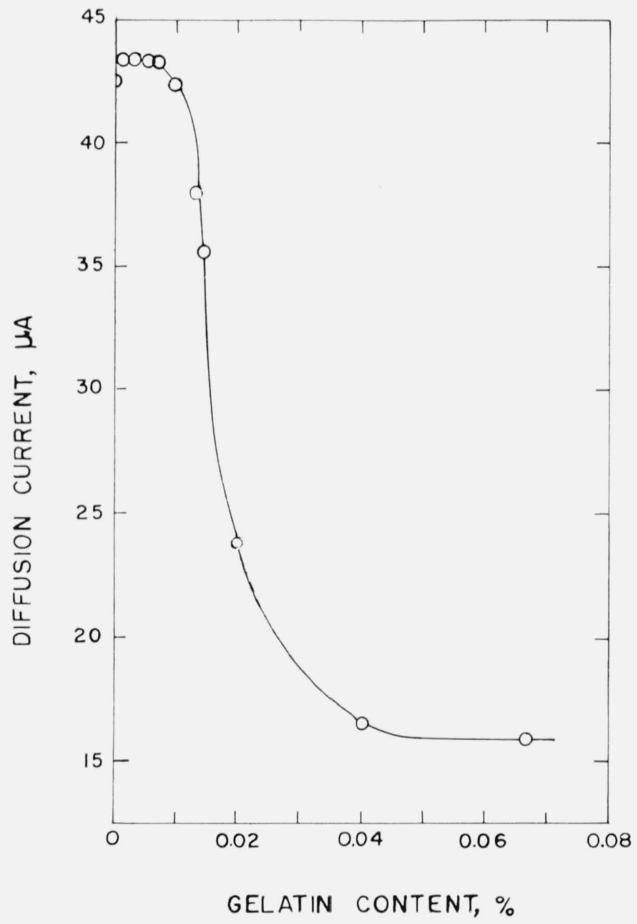

Figure 4. Effect of gelatin on the Ti(IV)-EDTA diffusion current.

attributable to the Ti-sulfate complex appears which cannot be completely removed on the further addition of ED'TA.

\subsection{Analysis of Pigments}

Table 2 presents data on the analysis of pure $\mathrm{TiO}_{2}$ as well as several pigments extracted from paint and a synthetie pigment extracted from a mixture of white lead, zinc oxide, titanium dioxide and bodied 
linseed oil. The standard method referred to in the table utilizes the Jones reductor method for the titanium analysis [3]. The precision and accuracy of the polarographic method is seen to be comparable to the standard volumetric method. In addition, the polarographic method is considerably faster, less subject to interferences and requires smaller sample weights.

TABLE 2. $\mathrm{TiO}_{2}$ Assay of NBS standard and paint pigments

\begin{tabular}{|c|c|c|c|}
\hline \multirow{2}{*}{ Sample } & \multicolumn{2}{|c|}{ Titanium dioxide content } & \multirow{2}{*}{$\begin{array}{l}\text { Difference in } \\
\text { methods }\end{array}$} \\
\hline & $\begin{array}{c}\% \text { by Volumetric } \\
\text { method }\end{array}$ & $\begin{array}{l}\% \text { by polaro- } \\
\text { graphic method }\end{array}$ & \\
\hline $\begin{array}{ll}1 & \text { Reagent grade } \\
2 & \text { NBS std. } \\
3 & \text { Synthetic pigment } \\
4 & \text { TT }-\mathrm{P}-102^{3} \\
5 & \text { TT-P }-115 \\
6 & \text { TT }-\mathrm{P}-115^{2} \\
7 & \text { TT }-\mathrm{P}-25 \\
8 & \text { TT-P-21 } \\
& \text { Average omitting run 5 }\end{array}$ & $\begin{array}{c}99.46 \pm 0.30^{4} \\
98.58 \pm 0.14 \\
22.71 \pm 0.19 \\
13.27 \pm 0.25 \\
13.84 \pm 0.16 \\
13.56 \pm 0.22 \\
8.62 \pm 0.11 \\
3.87 \pm 0.30\end{array}$ & $\begin{array}{r}\stackrel{(1)}{ } \\
98.57 \pm 0.06 \\
22.61 \pm 0.19 \\
13.41 \pm 0.22 \\
13.40 \pm 0.10 \\
8.54 \pm 0.09 \\
3.78 \pm 0.15\end{array}$ & $\left\{\begin{array}{r}-0.01 \\
-0.10 \\
+0.14 \\
-0.44 \\
-0.16 \\
-0.08 \\
-0.09 \\
0.10\end{array}\right.$ \\
\hline
\end{tabular}

1 Reagent Grade $\mathrm{TiO}_{2}$ used as standard material.

2 Analysis of same pigment used in Run 5 by spectrophotometric method (Beckman D. U. Spectrophotometer) to check large difference between volumetric and polarographic results.

3 Sample numbers refer to Federal Specification of the original paint from which pigment was extracted.

${ }_{4}^{4}$ A verage of at least four determinations on all samples; precision is expressed as standard de viation

${ }_{5}$ Standard Sample No. 154 certified as 98.7 percent $\mathrm{TiO}_{2}$.
The authors express their appreciation to George Marinenko and John K. Taylor of the National Bureau of Standards for their help and encouragement throughout the course of this work.

\section{References}

[1] D. K. Banerjee, C. D. Budke and F. D. Miller, Anal. Chem. 31, 1836 (1959).

[2] M. Codell, Analytical Chemistry of Titanium Metals and Compounds, p. 96 (Interscience Publishers, Inc., New York, 1959).

[3] Federal Test Method Standard No. 141, Method 7081 (GSA).

[4] R. L. Pecsok and E. F. Maverick, J. Am. Chem. Soc. 76 , 358 (1954).

[5] S. I. Sinyakova, Zh. Anal. Khim. 8, 333 (1953).

[6] Standard Methods of Chemical Analysis, 6th ed. II, Part B, ch. 37 (D. Van Nostrand Company, Inc., Princeton, N.J., 1963).

[7] H. H. Willard, L. L. Merritt, Jr., J. A. Dean, Instrumental Methods of Analysis, p. 544 (D. Van Nostrand Company, Inc., Princeton, N.J., 1958). 